\title{
High temperature patterns during seed maturation determine seed yield and quality in oilseed rape (Brassica napus L.) in relation to sulfur nutrition
}

\author{
Lethicia Almeida $^{1}$, Jean Christophe Avice ${ }^{1}$, Annette MORVAN-BERTRAND ${ }^{1}$, Marie \\ Hélène Wagner ${ }^{2}$, María Reyes González-Centeno ${ }^{3}$, Pierre-Louis Teissedre ${ }^{3}$, Jean Jacques \\ Bessoule $^{4}$, Marina Le Guédard ${ }^{5}$, Tae Hwan Kim ${ }^{6}$, Alain Mollier ${ }^{7}$, and Sophie \\ Brunel-Muguet ${ }^{1}$ \\ ${ }^{1} \mathrm{EVA}$ \\ ${ }^{2}$ GEVES \\ ${ }^{3}$ INRAE USC 1366 (Enologie \\ ${ }^{4}$ UMR5200 \\ ${ }^{5}$ LEB Aquitaine Transfert-ADERA \\ ${ }^{6}$ Chonnam National University College of Agriculture and Life Sciences \\ ${ }^{7}$ ISPA, Bordeaux Sciences Agro, INRAE
}

May 29, 2020

\begin{abstract}
High temperatures (HTs) during the crop reproductive stage impact seed yield and quality. The changing climate will require consideration of the effects of repeated HT events following evidence for non-additive effects due to beneficial stress memory or amplification of individual event effects. Maturing seeds of the sulfur (S)-demanding crop, oilseed rape, were exposed to several HT sequences that varied in intensity, duration and frequency at the onset of seed maturation. The effects of these sequences in combination with two contrasting $\mathrm{S}$ supplies are reported. The results indicated that (i) as the number of HT days in a sequence increased, fatty acid (FA) concentrations decreased, the proportion of unsaturated FAs decreased, seed membranes were damaged, desiccation tolerance was lost, and dormancy increased, regardless of event intensity and (ii) a mild stress event prior to heat peaks had a priming effect on desiccation tolerance and the phytohormones involved in HT-induced thermoinhibition. Low S nutrition amplified or alleviated the effects of the HT sequences due the requirement for S in enhancing seed storage synthesis or inducing stress memory-associated mechanisms. This work provides insights to define thermopriming protocols in relation to the timing of quality building processes and their respective optimal temperature.
\end{abstract}

\section{Introduction}

Evidence for increased frequency of stress events such as heat waves has been observed over recent decades. Based on the last IPCC report (Hoegh-Guldberg et al. 2018), heat waves are expected to become more frequent, to last longer and to increase in intensity during the reproductive phase of economically important crops (Trnka et al.2014; Christidis, Jones \& Stott 2015). These new climatic patterns have led to attempts to decipher crop behavior and final performance in the light of recurring stresses. While the effects of extreme/mild environmental stresses have been widely investigated from molecular to whole plant levels (Kotak et al. 2007; Wahid, Gelani, Ashraf \& Foolad 2007; Ohama et al. 2016), far fewer studies have tackled the issue of understanding the effects of their recurrence throughout the crop season. Indeed, the overall magnitude of the plant response to successive stresses might not match the effects induced by individual 
stressing events because (i) the first stress triggers physiological and metabolic adjustments that bring the plant to a modified status (including phenology) when the stress recurs, which leads to different responses to the second stress and (ii) a mild stress prior to further similar stresses can induce stress memory that lasts the duration of the crop season and is sometimes transmitted to offspring (Bruce, Matthes, Napier \& Pickett 2007; Kinoshita \& Seki 2014; Crisp, Ganguly, Eichten, Borevitz \& Pogson 2016; Kumar 2018). Stress memory is defined as the process of storage and retrieval of information acquired during an initial exposure to stress (Crisp et al. 2016; Hilker \& Schmülling 2019). This information acts as a priming process with beneficial effects when the stress recurs and it can lead to earlier, more rapid, intense, and sensitive responses that help plants to acclimate in changing environments (Kinoshita \& Seki 2014). Underlying mechanisms include epigenetic regulation, transcriptional priming, primed conformation of proteins, and/or specific hormonal or metabolic signatures. Several examples illustrate the benefits of stress memory, not only for the current generation of plants as they are challenged repeatedly during their own life cycle (i.e. intra-generational memory, Ding, Fromm \& Avramova 2012) but also for their offspring when faced with stresses similar to those experienced by the parent plants (i.e. transgenerational memory, Molinier, Ries, Zipfel \& Hohn 2006; Grootet al. 2016; Wang et al. 2016; Hatzig, Nuppenau, Snowdon \& Schießl 2018). This means that as the climate changes the effects of repeated stresses should be harnessed as a crop improvement strategy because this approach has promise for inducing acclimation to heat stress (Wang \& Liiang 2017).

In winter oleaginous crops, the reproductive phase occurs during spring, which might expose flowering, grain filling and grain maturation to high temperature events. Due to its indeterminate growth, the OSR plant displays flowers and growing pods in different proportions throughout the reproductive phase. Consequently, heat stress can impact reproductive organs by limiting their number and their size, which in turn leads to carbon (C) partitioning modification in favor of already developed organs that have passed the sensitive stage, and this makes analysis of the direct effects of heat stress on the organs more complex (Guilioni, Wery \& Tardieu 1997). While heat stress at flowering limits pollination (Sage et al. 2015) and/or induces early pod abortion resulting in yield losses in oilseed rape (Morrison \& Stewart 2002; Young, Wilen \& BonhamSmith 2004), heat stress that occurs during seed filling and maturation affects seed storage compounds quantitatively and qualitatively, leading to seed quality degradation. Few studies have reported the effects on seed quality in winter oilseed rape (OSR) of repeated heat stress events that might be erratic and fluctuate as predicted in climate change models (in field conditions, Deng \& Scarth 1998; Baux et al. 2013; in controlled conditions Aksouh, Jacobs, Stoddard \& Mailer 2001; Aksouh-Harradj, Campbell \& Mailer 2006). Seed quality encompasses a range of criteria related to nutritional and physiological characteristics (i.e. germination behaviors and storage capacity). In winter OSR, oil content, fatty acid (FA) profiles, and protein content are major nutritional criteria for edible oil and cakes used in human and animal consumption, respectively. OSR oil contains high polyunsaturated FA (PUFA) content compared to other oil crops, which makes it a healthy edible oil for human consumption (Aguirrezábal, Martre, Pereyra-Irujo, Echarte \& Izquierdo 2015). While contrasting variations have been observed in oil content according to the temperature intensity, the timing of stress exposure and the pools of seeds analyzed (main stem vs. bulk) (e.g. increased in BrunelMuguetet al. (2015); decreased in Canvin (1965); Aksouh et al.(2001); Aksouh-Harradj et al. (2006)), high temperatures are known to induce decreases in PUFAs in favor of saturated FAs (mainly C16:0 and C18:0) and monounsaturated FAs, and increases in the $\mathrm{C} 18: 2 / \mathrm{C} 18: 3$ ratio, as a result of temperature-triggered impairment of desaturase enzyme activity (i.e. oleic and linoleic desaturases) (Aksouh-Harradj et al. 2006; Baux, Hebeisen \& Pellet 2008; Bauxet al. 2013; Schulte et al. 2013; Brunel-Muguet et al. 2015; Gauthier et al. 2017). By contrast, seed nitrogen (N) and protein concentrations in the oil-free meal is usually negatively correlated with total oil content (Aksouh et al. 2001; Aksouh-Harradj et al. 2006) as observed in other oil crops (in soybean, N concentration Chebrolu et al. (2016); protein concentration, Dornbos \& Mullen (1992)). Additionally, other seed characteristics related to physiological quality, i.e. seed storage capacity and germination behavior, have been investigated, but not to any great extent (Brunel-Muguet et al. 2015). A drastic degradation of seed storage capacity has been observed using seed conductivity and the ratio of soluble sugars (sucrose and raffinose family oligosaccharides (RFOs)), abscisic acid (ABA), and gibberellic acid (GA3) as proxies (Bailly et al. 2001; Brunel-Muguet et al. 2015) in seeds from long-term heat-stressed mother plants. Other phytohormones were shown to be involved in the control of secondary dormancy, 
defined as failure in the germination process of mature and non-dormant seeds under adverse conditions (Pekrun, Lutman \& Baeumer 1997). Recent studies have highlighted the role of indole-3-acetic acid (IAA), whose concentrations increase in dormancy-induced seeds (Shu, Liu, Xie \& He 2016; Liu et al. 2019; Tuan, Yamasaki, Kanno, Seo \& Ayele 2019). Its high levels have also been correlated with high jasmonic acid (JA) in seeds as a consequence of both phytohormones interacting during the expression of indole glucosinolate biosynthesis genes (Liu et al. 2019). Although several studies have reported that salicylic acid (SA) enhanced germination in Arabidopsisseeds by reducing oxidative damage (Lee \& Park 2010; Chitnis et al. 2014), SA has also been shown to inhibit germination because of higher oxidative stress (Xie, Zhang, Hanzlik, Cook \& Shen 2007). In Brassica species, sulfur (S) nutrition determines yield components and seed quality because of their high S requirements throughout the crop cycle (D'Hooghe et al. 2014; Brunel-Muguet et al. 2015). In addition to its well-known implication in the synthesis and signaling of stress tolerance-controlling phytohormones (Hasanuzzaman et al. 2018), S might be involved in the acquisition of thermotolerance mediated by epigenetic regulation (Bokszczanin et al. 2013). This is based on evidence for S involvement in DNA methylation (through the role of S-adenosylmethionine (SAM) as a donor of methyl groups, Menget al. 2018), one of the key epigenetic markers that supports stress memory, thus making the analysis of S supply relevant in the context of epigenetic memory.

In our study we focused on the effects of high spring temperatures on seeds at the onset of maturation to deepen our knowledge of this seed quality-determining stage in relation to $\mathrm{S}$ nutrition. Our assumptions were that the effects of high temperature at the onset of seed maturation can greatly vary depending on whether plants are exposed to a mild heat stress event that primes them to withstand later heat peaks and that $\mathrm{S}$ nutrition might impact the ability of the plants to endure heat stress.

Overall, our experimental design addresses the following questions: (i) what are the quantitative effects of different high temperature sequences applied at the onset of seed maturation on seed yield, quality criteria and stress response indicators? (ii) to what extent do the effects of successive high temperature events applied to maturing pods differ from the effect of individual events? (iii) what are the underlying defense pathways triggered by temperature stress? (iv) is sulfur nutrition controlling heat stress responses through acquisition of thermotolerance?

\section{Materials and Methods}

\section{Experimental treatments and growth conditions}

Seeds of Brassica napus L. (cv. Aviso) were germinated in vermiculite in October 2016 under greenhouse conditions. After 5 weeks the seedlings were transplanted into pots containing perlite and vermiculite (2:1, $\mathrm{v} / \mathrm{v}$ ) for 7 weeks and seedlings were grown as described in Poisson et al. (2019). Afterwards, seedlings were subjected to a 12 -week period of vernalization in a climatic chamber maintained at $4^{\circ} \mathrm{C}$ (night) and $8^{\circ} \mathrm{C}$ (day) with artificial light during the day (10h day $/ 14 \mathrm{~h}$ night) and supplied with a $25 \%$ Hoagland solution without $\mathrm{N}$ or S. Then the plants were transferred into the greenhouse (Caen, France, 49deg11'09 N, 0deg21'32 W) and subjected to a thermoperiod of $20 \mathrm{degC}$ (day) and $15 \mathrm{degC}$ (night) without additional light. The plants were manually provided with two $\mathrm{N}$ applications with an $\mathrm{NH}_{4} \mathrm{NO}_{3}$ solution: 100 units (kg N/ha) at the end of vernalization (GS30, stem elongation, Lancashire et al. 1991) and 50 units of N at (GS60, bud formation) assuming a plant density of 40 plants. $\mathrm{m}^{-2}$. The two contrasting S supplies i.e. high S (HS) and low S (LS) were manually applied at the end of vernalization (GS30) as usually provided in the field. Plants were supplied with a solution of $\mathrm{MgSO}_{4}$ containing 75 (HS) and 25 (LS) units ( $\mathrm{kg} \mathrm{SO}_{3} / \mathrm{ha}$ ), which represent, respectively, $100 \%$ and $33 \%$ of the conventional supply. Four temperature modalities (T-modalities) were applied to plants at stage GS72 (i.e. $20 \%$ of the siliques having reached their maximum size) for 17 days. The T-modalities were designed to assess the effects of a mild temperature event prior to a more intense temperature event including daily heat peaks (Figure 1a, b). Our complete design allowed testing of the effects of three single-event sequences (SESs, $\bmod 2, \bmod 3$ and $\bmod 5)$ and of one combined-events sequence (CES, mod1): (i) an early period of mild warming (SES mod2, $25.3 \mathrm{deg} \mathrm{C}+-1.8 / 21.7 \mathrm{deg} \mathrm{C}+-0.7$ day (16h) /night (8h) applied for 5 full days) (ii) late heat peaks (SES, daily 31.4degC +-1.7 applied during the period of mild warming for 5 hours over 3 days -mod5- or 4 days-mod3) and (iii) the CES combining 
a mild warming period for 5 full days followed by a 5 -day natural thermoperiod $(\bmod 1$, mean, maximum and minimum temperatures being $15.7 \mathrm{deg} \mathrm{C}+-2.7,28.4 \mathrm{degC}$ and $11.5 \mathrm{deg} \mathrm{C}$, respectively) and eventually a 7-day mild thermoperiod including 4 heat interrupted by 3 day without a peak. The temperature intensities were chosen according to previous studies that used similar ranges to mimic mild and intense temperature treatments under controlled conditions (Aksouh-Harradj et al. 2006). Temperatures were recorded hourly with temperature probes (105T Campbell, Campbell Scientific Ltd., Leicestershire, UK).

Because mixed-age pods were present throughout the temperature sequences, on the day before the beginning of the temperature modalities exposure we labeled the plants' branches to identify the two categories of pods: (i) pods whose length was above $5 \mathrm{~cm}\left(\operatorname{pods}_{\mathrm{L}[?] 5 \mathrm{~cm}}\right)$ and (ii) pods whose length was shorter than $5 \mathrm{~cm}$ $\left(\operatorname{pods}_{\mathrm{L}<5 \mathrm{~cm}}\right)$. Indeed, prior experiments (data not shown) indicated that $5 \mathrm{~cm}$-long pods (or longer) contain seeds that have reached their final fresh weight, which coincides with late seed-filling development and the start of seed maturation (Borisjuk et al. 2013). When the pods started desiccating, they were carefully and individually wrapped with plastic pouches to avoid seed dispersal and the mixing of seeds between the pod categories.

Seed yield and components

At maturity, the seeds from the two categories of pods were weighed after freeze-drying for dry matter (DM) measurements. To determine the individual seed weight (Thousand Seed Weight (TSW)), we weighed and photographed seeds from both pod categories so as to score their number using image analysis algorithms (Image J Software).

Biochemical characteristics of seeds from $\operatorname{pods}_{\mathrm{L}[?] 5 \mathrm{~cm}}$

Seed carbon, nitrogen, and sulfur concentrations

Seeds of each individual plant $(\mathrm{n}=4)$ were pooled and dried for $48 \mathrm{~h}$ at $50 \mathrm{deg} \mathrm{C}$. The dried seeds were ground manually and the resulting powder (around $3 \mathrm{mg}$ ) was placed into tin capsules for analysis. The percentage of total carbon (C), nitrogen (N), and sulfur (S) per mg DM of the dried seeds were determined with a C/N/S analyzer (EA3000, Euro Vector, Milan, Italy) linked to a continuous flow isotope mass spectrometer (IRMS, Isoprime, GV Instrument, Manchester, UK).

\section{Seed fatty acid concentration}

Oil and fatty acid profile contents (C16:0, C18:0, C18:1, C18:2, C18:3, C20:0, C20:1 and C22:1) were determined from approximately $200 \mathrm{mg}$ of seeds from each plant $(\mathrm{n}=3)$ suspended in $1 \mathrm{~mL}$ of methanol/toluene/ $\mathrm{H}_{2} \mathrm{SO}_{4}$ solution $(100: 20: 2.5 ; \mathrm{v} / \mathrm{v})$ containing $\mathrm{C} 17: 0$ as internal standard $\left(5 \mu \mathrm{g} \mathrm{mL}^{-1}\right)$. After 1 hour of heating at $80{ }^{\circ} \mathrm{C}$ for transmethylation, fatty acid content was determined as described in Marchand et al. (2016).

\section{Seed storage protein concentration}

Protein analysis was performed in two steps: (i) protein extraction (ii) and the Bradford assay. For extraction, $20 \mathrm{~g}$ of ground seeds from plants $(\mathrm{n}=4)$ of each treatment was previously stored at $-20^{\circ} \mathrm{C}$. The next steps for extraction and the Bradford assays are described for leaves in Akmouche et al. (2019).

\section{Seed soluble sugar concentrations}

Soluble sugars were extracted from three replicates of $18 \mathrm{mg}$ from lyophilized and ground seeds (pooled from the four plants), with $1 \mathrm{~mL}$ methanol/water $(80: 20, \mathrm{v} / \mathrm{v}$ ) and $40 \mu \mathrm{L}$ melicitose used as the internal sugar standard. Glucose, fructose, sucrose, raffinose, and stachyose contents were quantified using HPLC (DIONEX ICS-3000) according to Brunel-Muguet et al. (2015). The [raffinose+stachyose]:sucrose ratio was used as an indicator of seed drying tolerance i.e. the higher the value, the more tolerant the seed is to desiccation (Bailly et al. 2001).

Analysis of stress signaling and seed dormancy-related phytohormones 
For each treatment ( $\mathrm{n}=3$ plants), 50mg of ground seeds were used to quantify 2-cis , 4-trans -abscisic acid (ABA), gibberellic acid (GA3), indole-3-acetic acid (IAA), jasmonic acid (JA), and salicylic acid (SA). Previously freeze-dried samples were mixed with $500 \mu \mathrm{L}$ of extraction solvent [2-propanol $/ \mathrm{H}_{2} \mathrm{O} /$ concentrated $\mathrm{HCl}(2: 1: 0.002, \mathrm{v} / \mathrm{v} / \mathrm{v})]$ and then analyzed by HPLC-MS as described in Pan, Welti \& Wang (2010). Because the dynamics of ABA and GA3 controls the balance between germination and dormancy, the ABA:GA3 ratio was used as a proxy for seed dormancy: germination balance (Debeaujon \& Koornneef 2000; Finkelstein 2013).

\section{Seed conductivity measurements}

Conductivity measurements were performed according to Brunel-Muguetet al. (2015). For each treatment ( $\mathrm{n}=4$ plants), measurements with the electrolytes were made with 20 pre-weighed seeds. At room temperature $\left(20^{\circ} \mathrm{C}\right)$, the seeds were placed in $5 \mathrm{~mL}$ of ultrapure water for 16 hours. Conductivity was measured with a portable electrochemical analyzer (Consort C931, UK).

\section{Determination of seed total phenolic content and antioxidant capacity}

Prior to the extraction, seeds from plants $(n=4)$ of each treatment were oven-dried at $60^{\circ} \mathrm{C}$ for at least 48 hours and then ground. The extraction procedure was adapted from Szydłowska-Czerniak, Amarowicz \& Szłyk (2010). Seeds were extracted with methanol: $\mathrm{H}_{2} \mathrm{O}(50: 50, \mathrm{v} / \mathrm{v})$ at a ratio of $20: 1(\mathrm{mg} / \mathrm{mL})$ by using mechanical stirring for $1 \mathrm{~h}$ at $25^{\circ} \mathrm{C}$. Total phenolic content was spectrophotometrically determined with a modified Folin-Ciocalteu method (González-Centeno, Comas-Serra, Femenia, Rosselló \& Simal 2015) and was expressed as the mean of six determinations in mg of sinapic acid equivalents per DM $g$ of seeds. Evaluation of the antioxidant capacity (ABTS assay value expressed as mg of trolox equivalents per $\mathrm{g}$ of seed DM) was carried out according to the methodology previously described by González-Centeno et al.(2012). Seed extracts were diluted at a ratio $1 / 4$ with methanol: $\mathrm{H}_{2} \mathrm{O}(50: 50, \mathrm{v} / \mathrm{v})$ and values were expressed as mg of trolox equivalents per g of seeds DM.

Statistical analyses

Results are expressed as the mean \pm se of $\mathrm{n}$ replicates used per treatment. The normality of the distribution and homogeneity of variances were previously tested (Shapiro-Wilk, Bartlett and Levene tests respectively). Two-Way ANOVA was performed for temperature (T), S, and $\mathrm{T} \times \mathrm{S}$ interaction effects on the measured variables, and classification of temperature modalities (T-modalities) was carried out by comparing averages (Tukey test). The differences between HS and LS for a given T-modality were tested with a t-test. These statistical analyses were performed with XLStat software. To determine the non-additive effects of temperature events (Figure 1a), we compared the relative effect of the events-combined sequence (mod1, CES) with the relative cumulated effects of the successive single-event sequence (SES, mod2 and mod3) on the measured variables under both S supplies. The relative effect was calculated as the increase or decrease relative to the control value. The relative cumulated effect of the successive SESs was then calculated by multiplying the two single relative effects $(\bmod 2 \mathrm{x} \bmod 3)$.

\section{Results}

Plant growth and yield components

Table 1 displays yield components i.e. seed number, TSW, and seed yield for the two categories of seeds collected from and pods $\mathrm{L}_{\mathrm{L}[?] 5 \mathrm{~cm}}$ and pods $\mathrm{L}_{\mathrm{L}<5 \mathrm{~cm}}$. The total seed yield (TSY, including seeds from both categories of pods) ranged from 8.71 to $9.92 \mathrm{~g}$ plant $^{-1}$, with no significant S effect. Under LS, no significant decreases in TSY were observed in the T-modalities whereas under HS, significant decreases were observed in mod1 ( $-24.2 \%$ relative to HS T-control) and $\bmod 2(-11.1 \%$ relative to HS T-control). These decreases were due to the seed yield from pods $\mathrm{L}_{\mathrm{L}<5 \mathrm{~cm}}$ since seed yield from $\operatorname{pods}_{\mathrm{L}[?] 5 \mathrm{~cm}}$ remained unchanged in T-control plants (Table 1). The total seed numbers were not impacted by the T-modality but a slight S-effect was observed $(\mathrm{p}<0.05)$, with LS values being $5 \%$ lower than HS values on average. This effect was also attributed to seeds from pods $\operatorname{Li}_{\mathrm{L}<5 \mathrm{~cm}}$ as the number of seeds from $\operatorname{pods}_{\mathrm{L}[?] 5 \mathrm{~cm}}$ was not impacted by $\mathrm{S}$ supply. The TSWs from $\operatorname{pods}_{\mathrm{L}<5 \mathrm{~cm}}$ were $3.33 \mathrm{~g}$ and $3.22 \mathrm{~g}$ in the HS and LS T-controls, respectively, while the equivalent pods $\mathrm{L}_{\mathrm{L}[?] 5 \mathrm{~cm}}$ 
values were 3.73 and $3.5 \mathrm{~g}$. For a given T-modality and a given $\mathrm{S}$ condition, the $\operatorname{pods}_{\mathrm{L}<5 \mathrm{~cm}}$ had a lower TSW than the pods ${ }_{\mathrm{L}[?] 5 \mathrm{~cm}}$, although the differences were significant only under LS for $\bmod 3$ and $\bmod 4$ (Table 1, t-tests not shown). Under both HS and LS, no T-modality effects on the TSW were observed in either pod categories. These results confirmed that (i) seeds from pods $\mathrm{L}_{\mathrm{L}[?] 5 \mathrm{~cm}}$ had reached the onset of seed maturation and (ii) seeds developing in $\operatorname{pods}_{\mathrm{L}<5 \mathrm{~cm}}$ or seeds from fertilized flowers that developed after the temperature sequences, all benefited from increased sink strength due to young pod abortion or reductions in late flowering.

In the following result sections, seed characteristics were measured solely on seeds from $\operatorname{pods}_{\mathrm{L}[?] 5 \mathrm{~cm}}$.

Nutritional seed quality criteria

Seed $C, N$ and $S$ concentrations

Table 2 displays $\mathrm{C}, \mathrm{N}$ and $\mathrm{S}$ seed concentrations. The seed $\mathrm{C}$ concentration $(\% \mathrm{C})$ was impacted by $\mathrm{T}$ modalities $(p<0.001)$ but no S effects were observed. The T-modalities only had an effect under HS, with mod1 and T-control ranked with the lowest (-7.4\% from HS T-control) and highest values, respectively. Similar to $\% \mathrm{C}$, the seed $\mathrm{N}$ concentration $(\% \mathrm{~N})$ was only affected by T-modalities $(p<0.001)$. Under both $\mathrm{S}$ conditions, extreme $\% \mathrm{~N}$ values were observed for mod1 and T-control, which had the highest and the lowest rankings, respectively $(+18.2 \%$ for HS mod1 compared to HS T-control, and $+21.9 \%$ for LS mod 1 compared to LS T-control). The SES events induced intermediate values of $\% \mathrm{~N}$ under both $\mathrm{S}$ supplies. These observations showed that the early mild stress had a positive effect over the late heat peaks, which suggested an alleviating effect. As expected, the seed $\mathrm{S}$ concentration $(\% \mathrm{~S})$ was significantly impacted by S supply $(p<0.001)$, which was mainly observed in T-control seeds and in mod3-seeds (decreases in $38.5 \%$ and $40 \%$, respectively, under LS). While no significant differences were observed among the T-modalities under HS, the \%S in mod1 was significantly higher than in T-control (37.5\%) under LS.

\section{Oil contents and fatty acid profiles}

Table 2 presents the total oil concentration and the FA profiles of saturated FAs (SFAs) and unsaturated FAs (UFAs). Total oil concentrations ranged from $30.10 \%$ to $45.11 \%$ of DM, with values under LS being significantly higher on average $(41.3 \% \mathrm{DM})$ than values under HS $(34.9 \% \mathrm{DM})(p<0.001)$. For a given Tmodality, S effects were significant except for T-control (Table 2). Effects of T-modalities were also observed $(p<0.05)$, although they were not significant under LS. Under HS, all T-modalities negatively impacted total oil concentration with mod1 and mod3 displaying the greatest decreases (-23.5\% and $-20.8 \%$, respectively, compared to the T-control) followed by $\bmod 2$ and $\bmod 4$, thus indicating lower negative effects of shorter stressing events, whether they were mild $(\bmod 2)$ or included heat peaks $(\bmod 4)$. The SFA concentration (including C16:0, C18:0, C20:0, C22:0) and the UFA concentration (including C16:1, C18:1, C18:2, C18:3, C20:1) ranged from 2.91 to $3.99 \%$ of DM and 27.19 to $41.11 \%$ of DM, respectively. A highly significant $\mathrm{S}$ effect was observed in both SFA and UFA concentrations (for SFAs 3.1\% DM in HS and 3.6\%DM in LS on average and for UFAs $31.8 \% \mathrm{DM}$ in HS and $37.7 \% \mathrm{DM}$ in LS on average). For a given T-modality, $\mathrm{S}$ effects were significant $(p<0.05)$ except for T-control (as observed for the total FA concentration) and mod1. Under HS, no significant T-modality effect was observed on SFA concentrations, while they varied under LS with mod1 and mod4 displaying the lowest (-9.1\%DM from LS T-control) and highest (+17.3\%DM from LS T-control) values, respectively. The significant T x S effect on SFA concentrations $(p<0.01)$ was mainly due to the different T-modality rankings observed under LS compared to similar ranking under HS. In contrast to the SFA concentrations, T-modality effects on UFA concentrations were observed only under HS, with mod1 and T-control having the lowest and highest values, respectively $(-24.7 \%$ of DM for mod1 compared to T-control). Overall, T-modality effects on total FA and UFA concentrations were observed only under HS and the effect on SFA concentrations was only under LS. Mod1 had the greatest impact on decreasing FA concentrations. Early mild stress did not alleviate the negative effects of later heat peaks on total FAs, SFAs and UFAs. In addition, the 4 late heat-peaks sequence had a greater impact than the 3 late heat-peaks sequence under HS (total FAs, UFAs). The S effects on total FAs, SFAs and UFAs were observed for each T-modality except T-control (three criteria) and mod1 (SFAs). Eventually, the C18:2/C18:3 ratio 
(i.e. $\omega 6: \omega 3$ ratio) was significantly impacted by the T-modalities under HS and LS (Table 2). The highest and lowest ratios were attributed, respectively, to mod1 and mod2 under HS (+12.8 and $-9.9 \%$ compared to the HS T-control) and $\bmod 3$ and $\bmod 2$ under LS $(+12.6 \%$ and $-7.7 \%$ compared to the LS T-control). In addition, the 3 late heat-peaks effect $(\bmod 4)$ was less negative than the early mild stress $(\bmod 2)$. These results indicated that the number of desaturations decreased with greater duration of stress exposure (mod1) and intensity and earliness of the heat stress event $(\bmod 3)$ under both $\mathrm{S}$ conditions.

\section{Seed storage protein concentrations}

The seed storage protein (SSP) concentrations ranged from $79.88 \mathrm{mg} / \mathrm{g}$ DM to $208.35 \mathrm{mg} / \mathrm{g} \mathrm{DM}$, with values under HS being significantly lower on average $(106.5 \mathrm{mg} / \mathrm{g} \mathrm{DM})$ than values under LS $(184.7 \mathrm{mg} / \mathrm{g} \mathrm{DM})$ (Table $2, p<0.001$ ). Except for $\bmod 2, \mathrm{~S}$ effects were observed for each T-modality. In contrast, no effects of T-modalities on seed N\% were observed, and its increase under higher temperature was the consequence of reductions in the number of growing sinks due to pod abortion, reduced seed filling and/or impaired pollination.

Seed quality-related physiological criteria

The soluble sugar composition as an indicator of desiccation tolerance acquisition

Table 3 presents the concentration of the main soluble sugar (SS) in seeds i.e. sucrose, raffinose and stachyose. Glucose and fructose were present as traces (data not shown). For the three main SSs, only T-modality effects were observed $(p<0.001)$, with different rankings among T-modalities according to the $\mathrm{S}$ condition. Under HS, sucrose, raffinose and stachyose concentrations were the highest in the T-control (together with mod4 for sucrose) and the lowest in $\bmod 2$ (together with mod1 for stachyose). In HS mod2, sucrose, raffinose and stachyose concentrations were respectively $54.8 \%, 52.3 \%$ and $51.1 \%$ lower than the HS T-control. Similarly, under LS, the SSs concentrations were the highest in T-control (together with mod4 for stachyose) and the lowest in mod1 (together with mod2 for sucrose). In LS mod1, raffinose and stachyose concentrations were respectively with $66.0 \%$ and $63.1 \%$ lower than in the LS T control. In LS mod2, sucrose concentrations was $63.9 \%$ than in LS-T control. Therefore, all T-modalities led to decreased SS concentrations under both $\mathrm{S}$ conditions. The greatest decreases were observed in early moderate stress $(\bmod 2)$ under HS and in the sequence combining early moderate stress and heat peaks $(\bmod 1)$ under LS. The [raffinose+stachyose]:sucrose ratio - used as a proxy of seed desiccation tolerance - ranged from $0.35(\bmod 3)$ to 0.43 (T-control) under HS and $0.34(\bmod 3)$ to $0.42(\bmod 4)$ under LS. These results indicate that whatever the S supply, the 4 late heat-peaks events were the most detrimental to acquisition of seed desiccation tolerance. However, these data also highlighted that the prior period of mild stress alleviated the negative effects of late heat peaks. This priming effect was not reduced under LS.

\section{Seed conductivity}

Seed conductivity values ranged from $0.66 \mu \mathrm{S} / \mathrm{mg}$ DM to $2.86 \mu \mathrm{S} / \mathrm{mg}$ DM with the mean HS and LS values being 1.43 and $1.27 \mu \mathrm{S} / \mathrm{mg} \mathrm{DM}$, respectively (Table 3 ). No effect of S supply was observed, whereas a highly significant T-modality effect was observed $(p<0.001)$. For both $\mathrm{S}$ supplies, extreme values were observed in T-control seeds (lowest values) and in mod1 seeds (highest values). While no significant differences between control, $\bmod 2, \bmod 3$ and $\bmod 4$ were observed under LS, different values were observed under HS with mod1 values being the highest (around $228.7 \%$ of the T-control) followed by mod2 $(47.1 \%)$. This indicates

that seed conductivity is highly responsive to the duration and the earliness of the stressing period because seeds from mod3 and mod4 that underwent the latest and shortest stressing events are the least negatively impacted.

\section{Phytohormone changes as indicators of temperature-induced seed dormancy}

The ABA:GA3 ratio ranged from 0.28 to 0.95 with significant lower values in HS than in LS (0.47 and 0.78 on average for HS and LS respectively) (Table 3). For each given T-modality, LS values were significantly higher than HS $(p<0.001)$ except for mod1. Different rankings among T-modalities according to S supply were observed with extreme values being in T-control (0.28) and in mod1 (0.74) under HS, and in mod2 
(0.60) and in mod4 (0.95) under LS. A high ratio indicates increased secondary seed dormancy, which is induced by thermoinhibition. As expected under high temperature, this ratio increased but under HS, the longest stressing period (mod1) was the most negatively impacted (highest value), whereas under LS the late heat-peaks events $(\bmod 3$ and $\bmod 4)$ induced the highest ratios. In addition, under LS, the early mild stress alleviated the negative effects of late heat peaks by lowering the ratio (lower value in mod1 than in $\bmod 3)$.

Seed concentrations of IAA, JA, and SA were measured to investigate their variation under the different temperature sequences and S supplies (Table 3). Consistent with the ABA:GA3 ratio, high concentrations of IAA were observed under high temperatures. The highest values were observed in mod3 under both $\mathrm{S}$ conditions (380.3 ng/g DW and $279.5 \mathrm{ng} / \mathrm{g}$ DW under HS and LS respectively) and the lowest values in mod2 under HS (-68.0\% of HS mod3 value) and in T-control under LS (-42.7\% of LS mod3 value). By contrast to the ABA:GA3 ratio, S limitation decreased IAA concentrations except under T-control and $\bmod 2$, which had levels of $+19.2 \%$ and $+73.7 \%$, respectively, in LS compared to HS (Table 3). Under HS conditions, the early mild stress (EMS) alleviated the strong increase in IAA concentration observed in the late 4 heat-peak sequence, thus suggesting a priming effect. SA concentrations also increased under heat stress for both S supplies. T-modality rankings were modified according to S supply, with the highest concentrations observed in mod 3 under HS $(+232.4 \%$ of HS T-control seeds) and in mod1 under LS $(+62.2 \%$ of LS T-control). As observed for IAA concentrations, SA concentrations decreased under LS (77.5 and 83.7 ng/g DM on average under LS and HS, respectively) except in the T-control (and to a greater extent in mod2). Similar to IAA concentrations, the EMS had an alleviating effect on the strong increase in the SA concentration under the late 4 heat-peak sequence $(\bmod 3)$, but this was under HS alone. In contrast to the IAA and SA concentrations, JA concentrations were not impacted by S supply, although differences between the HS and LS concentrations were observed for a given T- modality (Table 3). Indeed, while the highest and lowest values were mod1 $(2.32 \mathrm{ng} / \mathrm{g} \mathrm{DM})$ and T-control $(0.82 \mathrm{ng} / \mathrm{g} \mathrm{DM})$, respectively, under HS, the same was true for T-control $(1.66 \mathrm{ng} / \mathrm{g} \mathrm{DM})$ and $\bmod 2(1.07 \mathrm{ng} / \mathrm{g} \mathrm{DM})$ under LS. No alleviating effect of the early mild stress sequence was observed because mod1 seeds displayed either the highest JA concentration (in HS), or lower concentrations than in T-control (under LS) due to the S requirements for its synthesis and signaling.

Total phenolic content and antioxidant capacity in seeds as stress response indicators

Table 3 displays phenolic concentrations and the antioxidant activity (ABST values) measured in mature seeds from pods $\mathrm{L}_{\mathrm{L}[?] 5 \mathrm{~cm}}$. Phenolic concentrations ranged from 3.35 to $4.26 \mathrm{mg} \mathrm{SA} / \mathrm{g}$ seed DM with no significant effect of S supply. By contrast, significant T-modality effects $(p<0.05)$ were observed with different T-modality rankings according to S supply. Under HS, extreme seed phenolic concentrations were observed in mod2 ( $+4.0 \%$ compared to T-control) and in mod3 (-13.1\% compared to T-control), whereas under LS, extreme values were observed in $\bmod 2(+27.5 \%)$ and $\bmod 4$, which reached the low levels seen in the Tcontrol. These results indicate that under HS, increased seed phenolic concentrations were only observed when the plants were challenged with an early mild stress event at GS72, which contrasted with LS where all the T-modalities except mod4 induced higher seed phenolic concentrations. The antioxidant capacity measured with the ABTS assays revealed both S effects $(p<0.05)$ and T-modality effects $(p<0.01)$ (Table 3). T-modality rankings were similar to those observed for seed phenolic concentrations with extreme values for mod2 and mod3 seeds under HS, and mod2 and T-control seeds under LS. In addition, differences between HS and LS were observed for T-control (-18.2\% in LS compared to HS) and mod4 (-14.9\% in LS compared to HS). Overall, under both HS and LS, increased antioxidant capacities were observed in the EMS (mod2) while decreased antioxidant capacities (or levels similar to the T-control) were observed when the stress occurred later, and despite the stress's greater intensity (mod3 and $\bmod 4)$. In both S conditions the CES induced strong oxidative responses but they were lower than under the EMS alone, and it seemed as though the late heat peaks were beneficial enough to reverse the early mild stress-induced trend. S limitation led to decreased antioxidant capacity in the seeds (but this was not mediated through phenolic production), thus suggesting a crucial role for the $\mathrm{S}$ supply in limiting the oxidative damage that was enhanced under the high-temperature sequences. Taking into account the values of all the treatments, 
antioxidant capacities of the seeds were positively correlated to both phenolic concentration $(\mathrm{r}=0.93, p<0.001$ ) and the [raffinose+stachyose]:sucrose ratio $(\mathrm{r}=0.64, p<0.05)$ (supplemental data, Figure 1).

\section{Discussion}

Yield components were only impacted in reproductive plant parts developed after the stress

Yield components were not drastically impacted by the high temperature sequences applied at GS72. Under HS, no effect of temperature was observed on yield of pods ${ }_{L[?] 5 \mathrm{~cm}}$, meaning that the seeds from pods $\mathrm{s}_{\mathrm{L}[?] 5 \mathrm{~cm}}$ experienced a normal filling period. Therefore the impact of the heat sequences on total seed yield was the consequence of a yield reduction in seeds from $\operatorname{pods}_{\mathrm{L}<5 \mathrm{~cm}}$, which resulted from reductions in seed number and individual seed weight, even though neither component was significant. Indeed, abortions of young pods during the T-modality exposure and/or failure of pollination in the flowers present during this period might have occurred (Young et al. 2004). Changes in the reproductive strategy might also have reduced the incidence of late flowering (specific to indeterminate species) to the benefit of filling seeds in already developed pods. These observations are consistent with prior studies in pea (another indeterminate growth species) that demonstrated heat-stress modification of seed distribution along the main stem, which led to larger quantities of seeds on the basal parts than on the upper parts where reproductive organs are younger. These results explained the maintenance of seed yield from basal reproductive parts due to a higher allocation rate of carbohydrates and excluded the direct effects of heat stress on developing seeds (Guilioni, Wéry \& Lecoeur 2003). The non-significant effect of S on seed yield components, other than the total seed number, indicates that the LS supply in our study satisfied growth rate and yield requirements. Nevertheless, LS conditions impacted a few quality criteria related to nutritional value such as seed S content, SFAs and UFAs (Figure 2), as well as the concentrations of phytohormones involved in stress-induced secondary seed dormancy.

Priming effects are dependent on the timing of the stress events

Our initial objective was to pinpoint any beneficial effect from a mild stress event that occurs prior to later repeated intense heat peaks, i.e. whether a beneficial heat stress memory is generated due to induced thermosensitization. Our work highlights that the effects of the early stress event combined with late heat peaks are not straightforward and are determined by (i) whether the expected priming event occurs concomitantly with biosynthesis of seed storage compounds, and (ii) whether the temperature is adequate to enhance the targeted process. Figure 2 presented the T-modality effects on yield components of the SESs i.e. early mild, late heat peaks (3 or 4) and the CES according to S supply, and nutritional and physiological quality criteria measured in maturing seeds. Most T-modality effects were S supply specific and for some of them opposite effects were observed (i.e. the ABA:GA3 ratio irrespective of the T-modality, the [raffinose+stachyose]:sucrose ratio in the 3 late heat peaks) thus highlighting the complexity of interactions between stress temperature features and $\mathrm{S}$ availability. The CES decreased seed C, FA and PUFA concentrations under HS. These observations suggest that the duration of the heat stress sequence (i.e. the combined sequence having the more number of days above natural temperature over the 17 days of treatment) was the most detrimental feature for maintaining $\mathrm{C}$ concentration and hence FA synthesis since the CES induced a greater decrease than the early mild stress or the late heat peaks alone. These results correlate with earlier studies (Aksouhet al. 2001; Aksouh-Harradj et al. 2006) of intense temperature exposure during seed maturation but contrast with others that highlighted increased total FA contents under a long mild stressing event (Brunel-Muguet et al. 2015). Disruption of FA accumulation in OSR has been shown under intense heat stress across a range of temperatures similar to those imposed under our heat-peak conditions, and this was a consequence of photosynthesis inhibition and downregulation of BnWRI1 gene expression, which is a key regulator of FA biosynthesis (Ruuska, Girke, Benning \& Ohlrogge 2002; Huang et al. 2019). Our results also revealed higher total FA, SFA, and UFA concentrations under LS, but only in specific high-temperature sequences (Figure 2), which contrasted with prior results (Brunel-Muguet et al. 2015). These differences can be explained in the current work by the lower S supply and the different approaches to seed sampling and analysis (on maturing seeds exposed to the heat sequence). The negative effects of high temperature on total FAs and UFAs also indicated that (i) FA biosynthesis was concomitant with the 17-day high-temperature treatment starting approximately 3 
weeks after the onset of flowering (Figure 1b), with FA levels rising during the late storage stage (i.e. 20 after pollination (Niu et al. 2009; Borisjuk et al.2013)) and (ii) the later the heat peaks, the lower the effects. The increased $\omega 6: \omega 3$ ratio under the CES and late heat peaks is also detrimental to oil quality, and is known to result from impaired functioning of the oleic and linoleic desaturases (Aksouh-Harradjet al. 2006).

As usually observed, the accumulations of lipids and proteins (herein linked to seed $\mathrm{N}$ concentration) are negatively correlated because they are competitive processes that have spatial and temporal overlaps (Grami \& Stefansson 1977; Borisjuk et al. 2013). Therefore, while the CES decreased the total FA concentration, it increased the seed $\mathrm{N}$ concentration under both $\mathrm{S}$ supplies. However no effects of the late heat peaks were observed under HS, suggesting that the positive increase observed in the CES could not be interpreted as a priming effect that helps to overcome later negative effects. This supports the hypothesis of compensatory effects between the pods that were maturing and the ones that were still developing during the 17-day temperature sequence. Indeed, seed $\mathrm{N}$ accumulation was likely to be impaired in filling seeds, and this resulted in $\mathrm{N}$ reallocation towards filled and maturing seeds. In contrast, while the SSP concentrations were not increased under high temperature, they increased under LS as previously observed (Brunel-Muguet et al. 2015) except in the early mild stress.

Ultimately, seed physiological characteristics were also highly dependent on the features of the high temperature sequence (duration, intensity), which shapes the dynamics of biosynthesis of storage compounds involved in seed dormancy and stress tolerance. Seed storability and desiccation tolerance can be evaluated by two measured proxies i.e. membrane conductivity and the [raffinose+stachyose]:sucrose ratio. Our results highlighted strong effects of high temperature on seed conductivity, indicating degradation of membrane permeability. However, the [raffinose+stachyose]:sucrose ratio remained unchanged in the CES and in the EMS, which instead suggests acquisition of desiccation tolerance under both S supplies. The beneficial effects of the EMS on desiccation tolerance were maintained throughout the late heat peaks, indicating a more pronounced priming effect under HS. Several phytohormones control seed dormancy, as indicated by the ABA:GA3 ratio, which has been shown to vary according to stresses imposed on the parent plant during seed development (Brunel-Muguet et al. 2015). A high ABA:GA3 ratio indicates higher seed dormancy, which is expected for efficient seed storage before favorable environmental conditions permit the seeds to germinate. The EMS and the late heat peaks modified the ABA:GA3 ratio but to a greater extent in the late 4 heat peaks. These observations also indicate that the timing of the stress exposure is determining i.e. if the stressing event occurs after a given seed compound has been synthesized, and the stressing temperature does not lead to degradation of the compound, no temperature effect will be observed on the synthesized compound. This rule can be extended to an expected priming event, which can occur too early before or too late after the compound's biosynthesis. Therefore, our results raised questions about what is the optimal temperature for the biosynthesis and maturation processes and how synchronization between these processes and the temperature event occurs so that the expected effects (negative, positive or beneficial priming) can be observed.

Evidence for non-additive effects of successive heat stress events as a consequence of stress response amplification or the priming effect

Most measured variables illustrated the non-additive effects of the successive events, meaning that the cumulative impact of the respective effects of each SES (e.g. mod2, mod3, SEScml) differed from the effect of CES $(\bmod 1)$. When a mismatch was observed, the effect of the CES was either (i) higher than the effects of the SEScml or (ii) lower than the effects of the SEScml. Under HS, the CES effects (absolute value) on total yield, seed conductivity, the ABA:GA3 ratio and seed $\mathrm{N}$ concentration were higher than the SEScml effects, whereas the CES effects were lower for the [raffinose+stachyose]:sucrose ratio and the FA concentration (Table 4), but to a lesser extent for the FAs. Similar mismatches were observed under LS for seed conductivity, the ABA:GA3 ratio (higher CES effects than SEScml effects), FA concentration (lower CES effects than SEScml effects) but not for total yield, the [raffinose+stachyose]:sucrose ratio, for which the CES effects were lower than (or equal to) the SEScml effects. Therefore, this analysis highlights that $\mathrm{S}$ availability determines the magnitude (value and direction of variation) of the mismatches between the 


\section{SEScml and CES effects.}

Modulation of antioxidant capacities according to features of the high temperature sequences

Heat stress is known to trigger oxidative bursts that lead to a wide spectrum of responses including enzymatic and non-enzymatic components such as polyphenols, hormones and sugars, which have been shown to scavenge ROS (Nishizawa, Yabuta \& Shigeoka 2008; Soengas, Rodríguez, Velasco \& Cartea 2018; Serrano, Ling, Bahieldin \& Mahfouz 2019; Soares, Carvalho, Azevedo \& Fidalgo 2019). In our study, measurements of the antioxidant capacity indicated complex results that differed according to the $\mathrm{S}$ supply. In the non-limiting $\mathrm{S}$ conditions the greatest increase was not observed under the CES or late heat peaks, but it occurred following the EMS event. These observations correlated with seed polyphenol concentrations, which displayed similar rankings. However, other studies have reported the enhancement of subcellular antioxidant activities using several antioxidant enzymes as proxies (superoxide dismutase, glutathione reductase, and peroxidase in mitochondria and chloroplasts of wheat leaves) under multiple heat priming sequences prior to later high temperatures (Wang et al.2014), which might not be observed with the antioxidant capacity tests used herein. In addition, the concentrations of raffinose and stachyose, which have been reported to protect against oxidative damage (Nishizawaet al. 2008), were not increased under EMS under either of the S conditions, and so it was not possible to ascertain their role in the antioxidant defense pathways. However, this observation should be interpreted carefully regarding the timing and optimal biosynthesis of sugars within the maturing seeds, as previously discussed (Baud, Boutin, Miquel, Lepiniec \& Rochat 2002; Leprince, Pellizzaro, Berriri \& Buitink 2017). Indeed, our results might suggest that the temperature sequences (whether mild or intense) were above the temperature threshold of the stepwise transfer reactions involving raffinose synthase and stachyose synthase, leading to impairment of sugar biosynthesis (Gangl, Behmüller \& Tenhaken 2015). Nevertheless, because the EMS had little to no negative impacts on the seed quality criteria (Tables 2 and 3) and it triggered the highest levels of antioxidant capacity and polyphenols and low levels of RFOs, the induced antioxidant response to the mild stress might rely on an effective stress response mediated by specific components of the non-enzymatic antioxidant machinery (mainly dealing with polyphenols and not sugars).

Phytohormones, thermotolerance and thermoinhibition

Phytohormones such as IAA, JA and SA have been demonstrated to interact with ROS during stress tolerance as stress-signaling cues (Clarke, Mur, Wood \& Scott 2004; Sharma \& Laxmi 2016; Bielach, Hrtyan \& Tognetti 2017; Balfagón et al. 2019; Prerostova et al. 2020) and have also been linked to stress thermotolerance (Clarke et al.2009; Shu et al. 2016; Tuan et al. 2019) because increases in the levels of these compounds under high temperature are associated with greater stress-induced dormancy and thermoinhibition (Toh et al. 2012). In our study, we observed drastic increases in IAA, JA, and SA in mature seeds collected from pods exposed to heat stress at the onset of maturation under non-limiting $\mathrm{S}$ conditions (Table 3). The 4 late heat peaks induced the greatest increase in IAA and SA, while the CES (which had the longest accumulated days of above-natural temperature) induced the greatest changes in the ABA:GA3 ratio and JA. Therefore, the early mild stress allowed the negative effect of the late heat peaks on IAA and SA concentrations to be alleviated under the non-limiting S supply, thus leading to lower thermoinhibition. In addition, the late 3 heat peaks sequence had less effect than the late 4 heat peaks on IAA and SA, which also suggests that the shorter the period of intense stressing, the lower the impact on the seed concentration.

JA and SA were also reported to confer basal thermotolerance, which is defined as the ability to survive sub- or supra-optimal temperatures (Clarke et al. 2009; Bokszczanin et al. 2013). However, while JA was shown to be involved in acclimation to heat stress (Balfagón et al. 2019), SA was not essential for acquired thermotolerance (Clarke et al. 2004). These results suggest that lower levels of SA and higher JA levels could be expected under priming conditions than under non-primed conditions. Consistently, our results highlighted lower concentrations of SA and higher JA concentrations in the CES than in the late 4 heat peaks, which suggests that an early prior mild stress promoted acquired thermotolerance under the non-limiting S supply.

Impact of S availability on thermotolerance acquisition

Firstly, the level of S limitation in our assay was mild enough to impact only a few nutritional (FA-related, 
SSPs) and physiological (ABA:GA3 ratio) quality criteria (Figure 2). By contrast, the indicators of the stress response displayed contrasting temperature modality rankings according to the S supply (Table 3). Our results pinpointed increased antioxidant responses under the 3 late heat peaks and under natural thermoperiod in plants exposed to limiting S supply (Table 3). Nevertheless, S nutrition has been reported to improve antioxidant defenses due to S-containing antioxidant compounds such as the redox-active cysteine residues of glutathione and thioredoxin (Mukwevho, Ferreira \& Ayeleso 2014) and also specific phytohormones (Xia et al. 2015; Bashir et al. 2015; Hasanuzzaman et al. 2018). Therefore, it can be assumed that phytohormones such as IAA, SA and JA boosted the antioxidant responses and that their biosynthesis and/or signaling roles (reviewed in Hasanuzzaman et al. 2018) . were enhanced under S limitation. Indeed, IAA biosynthesis relies on the effectiveness of $\mathrm{S}$ metabolism via adequate levels of glutathione (Kopriva et al. 2016) and is improved when S is limiting (Nikiforova et al. 2003); JA signaling is dependent on S-containing metabolites (Park et al. 2013) and its synthesis is enhanced under S restriction (D'Hooghe, Escamez, Trouverie \& Avice 2013); SA is also known to interact with S during SA homeostasis regulation (Baek et al. 2010). Likewise, our results showed that the enhanced antioxidant responses in S-restricting conditions, especially under the CES and the EMS, correlated with higher concentrations of IAA and JA but not SA. Altogether, these observations not only reflect the direct effects of S restriction on phytohormone synthesis but also the interactions between their specific temperature threshold for synthesis and the features of the temperature sequences (i.e. intensity, duration and period), leading to biosynthesis impairment if these factors are not optimal, regardless of the level of S.

\section{Conclusion}

Our study analyzed the effects of repeated high temperature events at the onset of seed maturation on seed nutritional and physiological quality under induced thermotolerance. Our results pinpointed three aspects of thermo-sensitization for further investigation: (i) the synchronization between the expected thermopriming event and the underlying biosynthesis and maturation processes specific to the targeted storage compound, (ii) the optimal temperature to promote a targeted process and (iii) the non-additive effects of repeated stressing events as a result of positive stress memory or cumulative negative impacts of successive events. Our experiments were also designed to observe whether S nutrition (which is essential to Brassica species) interfered with expected priming effects. Nevertheless, we could only verify this hypothesis in a few priming effects that were observed via an indicator of desiccation tolerance ([raffinose+stachyose:sucrose]), which slightly diminished under $\mathrm{S}$ restriction. This raises the question of the direct role of $\mathrm{S}$ in the cascade of events leading to these sugars biosynthesis and the indirect role of $\mathrm{S}$ in stress memory mediated by epigenetic regulation. In contrast, S restriction optimized seed oil concentrations in stress-exposed maturing seeds, especially when the stress was delayed, thus highlighting the need to satisfy $\mathrm{S}$ requirements in certain climatic contexts.

Overall, we foresee the need for trade-offs to optimize quality criteria that are dependent on features of temperature such as intensity, frequency and timing of application. They should consider S supply which limitation or at least adjusted levels can either improve seed quality criteria (e.g. oil contents, UFAs) in temperature-stressed maturing seed, lessen the positive effects of a priming event (e.g. desiccation tolerance) or amplify the negative effects of high temperature stress when applied at sensitive stages during the maturation process (e.g. indicator of seed dormancy).

\section{Acknowledgments}

This study was supported by the Environment and Agronomy division of INRAE (funding "Pari Scientifique INRAE"). The authors would like to thank Magali Bodereau, Josiane Pichon, Josette Bonnefoy, Marine Lechevrel, Théo Lemercier, Julien Mignot and Christophe Muguet for their technical assistance and help with data analysis. They also thank Dr. Bae for the hormone analyses, Nicolas Elie from the CEMABIO platform for seed image analysis and Laurence Cantrill for editing the manuscript and providing relevant suggestions.

Bibliography 
Aguirrezábal L., Martre P., Pereyra-Irujo G., Echarte M.M. \& Izquierdo N. (2015) Improving grain quality: ecophysiological and modeling tools to develop management and breeding strategies. Crop Physiology , 423465 .

Akmouche Y., Cheneby J., Lamboeuf M., Elie N., Laperche A., Bertheloot J., .. Brunel-Muguet S. (2019) Do nitrogen- and sulphur-remobilization-related parameters measured at the onset of the reproductive stage provide early indicators to adjust $\mathrm{N}$ and $\mathrm{S}$ fertilization in oilseed rape (Brassica napus L.) grown under Nand/or S-limiting supplies? Planta 250, 2047-2062.

Aksouh-Harradj N.M., Campbell L.C. \& Mailer R.J. (2006) Canola response to high and moderately high temperature stresses during seed maturation.Canadian Journal of Plant Science 86 , 967-980.

Aksouh N.M., Jacobs B.C., Stoddard F.L. \& Mailer R.J. (2001) Response of canola to different heat stresses. Australian Journal of Agricultural Research 52, 817-824.

Baek D., Pathange P., Chung J., Jiang J., Gao L., Oikawa A., . . Shi H. (2010) A stress-inducible sulphotransferase sulphonates salicylic acid and confers pathogen resistance in Arabidopsis. Plant, Cell \& Environment 33, 1383-1392.

Bailly C., Audigier C., Ladonne F., Wagner M.H., Coste F., Corbineau F. \& Come D. (2001) Changes in oligosaccharide content and antioxidant enzyme activities in developing bean seeds as related to acquisition of drying tolerance and seed quality. Journal of Experimental Botany52 , 701-708.

Balfagon D., Sengupta S., Gomez-Cadenas A., Fritschi F.B., Azad R.K., Mittler R. \& Zandalinas S.I. (2019) Jasmonic Acid Is Required for Plant Acclimation to a Combination of High Light and Heat Stress. Plant physiology 181, 1668-1682.

Bashir H., Ibrahim M.M., Bagheri R., Ahmad J., Arif I.A., Baig M.A. \& Qureshi M.I. (2015) Influence of sulfur and cadmium on antioxidants, phytochelatins and growth in Indian mustard. AoB PLANTS7 .

Baud S., Boutin J.P., Miquel M., Lepiniec L. \& Rochat C. (2002) An integrated overview of seed development in Arabidopsis thaliana ecotype WS. Plant Physiology and Biochemistry 40 , 151-160.

Baux A., Colbach N., Allirand J.M., Jullien A., Ney B. \& Pellet D. (2013) Insights into temperature effects on the fatty acid composition of oilseed rape varieties. European Journal of Agronomy49 , 12-19.

Baux A., Hebeisen T. \& Pellet D. (2008) Effects of minimal temperatures on low-linolenic rapeseed oil fatty-acid composition. European Journal of Agronomy 29 , 102-107.

Bielach A., Hrtyan M. \& Tognetti V.B. (2017) Plants under stress: Involvement of auxin and cytokinin. International Journal of Molecular Sciences $\mathbf{1 8}$.

Bokszczanin K., Fragkostefanakis S., Bostan H., Bovy A., Chaturvedi P., Chiusano M.L., ... Winter P. (2013) Perspectives on deciphering mechanisms underlying plant heat stress response and thermotolerance.Frontiers in Plant Science $\mathbf{4}, 315$.

Borisjuk L., Neuberger T., Schwender J., Heinzel N., Sunderhaus S., Fuchs J., .. Rolletschek H. (2013) Seed architecture shapes embryo metabolism in oilseed rape. The Plant cell $\mathbf{2 5}, 1625-40$.

Bruce T.J.A., Matthes M.C., Napier J.A. \& Pickett J.A. (2007) Stressful "memories" of plants: Evidence and possible mechanisms. Plant Science 173, 603-608.

Brunel-Muguet S., D’Hooghe P., Bataille M.-P., Larre C., Kim T.-H., Trouverie J., .. Durr C. (2015) Heat stress during seed filling interferes with sulfur restriction on grain composition and seed germination in oilseed rape (Brassica napus L.). Frontiers in Plant Science 6 .

Canvin D.T. (1965) The effect of temperature on the oil content and fatty acid composition of the oils from several oil seed crops. Canadian Journal of Botany 43, 63-69. 
Chebrolu K.K., Fritschi F.B., Ye S., Krishnan H.B., Smith J.R. \& Gillman J.D. (2016) Impact of heat stress during seed development on soybean seed metabolome. Metabolomics 12, 1-14.

Chitnis V.R., Gao F., Yao Z., Jordan M.C., Park S. \& Ayele B.T. (2014) After-ripening induced transcriptional changes of hormonal genes in wheat seeds: The cases of brassinosteroids, ethylene, cytokinin and salicylic acid. PLOS ONE $\mathbf{9}, 1-14$.

Christidis N., Jones G.S. \& Stott P.A. (2015) Dramatically increasing chance of extremely hot summers since the 2003 European heatwave.5 , 46-49.

Clarke S.M., Cristescu S.M., Miersch O., Harren F.J.M., Wasternack C. \& Mur L.A.J. (2009) Jasmonates act with salicylic acid to confer basal thermotolerance in Arabidopsis thaliana. New Phytologist182 , 175-187.

Clarke S.M., Mur L.A.J., Wood J.E. \& Scott I.M. (2004) Salicylic acid dependent signaling promotes basal thermotolerance but is not essential for acquired thermotolerance in Arabidopsis thaliana. Plant Journal $\mathbf{3 8}$ , 432-447.

Crisp P.A., Ganguly D., Eichten S.R., Borevitz J.O. \& Pogson B.J. (2016) Reconsidering plant memory: Intersections between stress recovery, RNA turnover, and epigenetics. Science Advances 2 , e1501340-e1501340.

D'Hooghe P., Dubousset L., Gallardo K., Kopriva S., Avice J.-C. \& Trouverie J. (2014) Evidence for Proteomic and Metabolic Adaptations Associated with Alterations of Seed Yield and Quality in Sulfur-limited Brassica napus L. Molecular \& Cellular Proteomics 13, 1165-1183.

D'Hooghe P., Escamez S., Trouverie J. \& Avice J.-C. (2013) Sulphur limitation provokes physiological and leaf proteome changes in oilseed rape that lead to perturbation of sulphur, carbon and oxidative metabolisms. BMC plant biology $\mathbf{1 3}, 23$.

Debeaujon I. \& Koornneef M. (2000) Gibberellin Requirement for Arabidopsis Seed Germination Is Determined Both by Testa Characteristics and Embryonic Abscisic Acid 1 .

Deng X. \& Scarth R. (1998) Temperature effects on fatty acid composition during development of lowlinolenic oilseed rape (Brassica napus L.). Journal of the American Oil Chemists' Society 75 , 759-766.

Ding Y., Fromm M. \& Avramova Z. (2012) Multiple exposures to drought "train" transcriptional responses in Arabidopsis. Nature communications 3, 740 .

Dornbos D.L. \& Mullen R.E. (1992) Soybean seed protein and oil contents and fatty acid composition adjustments by drought and temperature.Journal of the American Oil Chemists Society 69 ,228-231.

Finkelstein R. (2013) Abscisic Acid Synthesis and Response. The Arabidopsis Book 11, e0166.

Gangl R., Behmuller R. \& Tenhaken R. (2015) Molecular cloning of AtRS4, a seed specific multifunctional RFO synthase/galactosylhydrolase in Arabidopsis thaliana. Frontiers in Plant Science $6,789$.

Gauthier M., Pellet D., Monney C., Herrera J.M., Rougier M. \& Baux A. (2017) Fatty acids composition of oilseed rape genotypes as affected by solar radiation and temperature. Field Crops Research 212 , 165-174.

Gonzalez-Centeno M.R., Comas-Serra F., Femenia A., Rossello C. \& Simal S. (2015) Effect of power ultrasound application on aqueous extraction of phenolic compounds and antioxidant capacity from grape pomace (Vitis vinifera L.): Experimental kinetics and modeling. Ultrasonics Sonochemistry 22 , 506-514.

Gonzalez-Centeno M.R., Jourdes M., Femenia A., Simal S., Rossello C. \& Teissedre P.-L. (2012) Proanthocyanidin Composition and Antioxidant Potential of the Stem Winemaking Byproducts from 10 Different Grape Varieties (Vitis vinifera L.). Journal of Agricultural and Food Chemistry 60 , 11850-11858.

Grami B. \& Stefansson B. (1977) Gene action for protein and oil content in summer rape. Canadian Journal of Plant Science $\mathbf{5 7}$. 
Groot M.P., Kooke R., Knoben N., Vergeer P., Keurentjes J.J.B., Ouborg N.J. \& Verhoeven K.J.F. (2016) Effects of Multi-Generational Stress Exposure and Offspring Environment on the Expression and Persistence of Transgenerational Effects in Arabidopsis thaliana. PLoS ONE11, 1-16.

Guilioni L., Wery J. \& Lecoeur J. (2003) High temperature and water deficit may reduce seed number in field pea purely by decreasing plant growth rate. Functional Plant Biology 30 , 1151-1164.

Guilioni L., Wery J. \& Tardieu F. (1997) Heat stress-induced abortion of buds and flowers in pea: Is sensitivity linked to organ age or to relations between reproductive organs? Annals of Botany80 , 159-168.

Hasanuzzaman M., Bhuyan M.H.M.B., Mahmud J.A., Nahar K., Mohsin S.M., Parvin K. \& Fujita M. (2018) Interaction of sulfur with phytohormones and signaling molecules in conferring abiotic stress tolerance to plants. Plant Signaling and Behavior $13,1-5$.

Hatzig S. V., Nuppenau J.N., Snowdon R.J. \& Schiessl S. V. (2018) Drought stress has transgenerational effects on seeds and seedlings in winter oilseed rape (Brassica napus L.). BMC Plant Biology18 , 1-13.

Hilker M. \& Schmulling T. (2019) Stress priming, memory, and signalling in plants. Plant Cell and Environment $42,753-761$.

Hoegh-Guldberg O., Jacob D., Taylor M., Bindi M., Brown S., Camilloni I., ... Zhou G. (2018) Impacts of $1.5^{\circ} \mathrm{C}$ Global Warming on Natural and Human Systems. In In: Global Warming of 1.5degC. An IPCC Special Report on the impacts of global warming of $1.5 \mathrm{deg} C$ above pre-industrial levels and related global greenhouse gas emission pathways, in the context of strengthening the global response to the threat of climate cha . (eds V. Masson-Delmotte, P. Zhai, H. Portner, D. Roberts, J. Skea, P. Shukla, ... T. Waterfield), p. $32 \mathrm{pp}$.

Huang R., Liu Z., Xing M., Yang Y., Wu X., Liu H. \& Liang W. (2019) Heat Stress Suppresses Brassica napus Seed Oil Accumulation by Inhibition of Photosynthesis and BnWRI1 Pathway. Plant and Cell Physiology $60,1457-1470$.

Kinoshita T. \& Seki M. (2014) Epigenetic memory for stress response and adaptation in plants. Plant and Cell Physiology 55 , 1859-1863.

Kopriva S., Talukdar D., Takahashi H., Hell R., Sirko A., D’Souza S.F. \& Talukdar T. (2016) Editorial: Frontiers of Sulfur Metabolism in Plant Growth, Development, and Stress Response. Frontiers in Plant Science 6, 1220 .

Kotak S., Larkindale J., Lee U., von Koskull-Doring P., Vierling E. \& Scharf K.D. (2007) Complexity of the heat stress response in plants. Current Opinion in Plant Biology 10, 310-316.

Kumar S. (2018) Epigenetic memory of stress responses in plants.J. Phytochem. Biochem 2, e102.

Lancashire P.D., Bleiholder H., Van Den Boom T., Langeluddeke P., Stauss R., Weber E., Witzenberger A. (1991). A uniform decimal code for growth stages of crops and weeds. Annals of applied Biology119, 561-601.

Lee S. \& Park C.-M. (2010) Modulation of reactive oxygen species by salicylic acid in arabidopsis seed germination under high salinity.Plant Signaling \& Behavior 5 , 1534.

Leprince O., Pellizzaro A., Berriri S. \& Buitink J. (2017) Late seed maturation: Drying without dying. Journal of Experimental Botany68, 827-841.

Liu L., Liu F., Chu J., Yi X., Fan W., Tang T., ... Zhao X. (2019) A transcriptome analysis reveals a role for the indole GLS-linked auxin biosynthesis in secondary dormancy in rapeseed (Brassica napus L.).BMC Plant Biology 19, 1-18.

Marchand L., Pelosi C., Gonzalez-Centeno M.R., Maillard A., Ourry A., Galland W., .. Brunel-Muguet S. (2016) Trace element bioavailability, yield and seed quality of rapeseed (Brassica napus L.) modulated by 
biochar incorporation into a contaminated technosol.Chemosphere $\mathbf{1 5 6}$.

Meng J., Wang L., Wang J., Zhao X., Cheng J., Yu W., .. Gong Z. (2018) METHIOnINE ADENOSYLTRANSFERASE 4 mediates DNA and histone methylation. Plant Physiology 177, pp.00183.2018.

Molinier J., Ries G., Zipfel C. \& Hohn B. (2006) Transgeneration memory of stress in plants. Nature 442 , 1046-1049.

Morrison M.J. \& Stewart D.W. (2002) Heat stress during flowering in summer Brassica. Crop Science 42 , $797-803$.

Mukwevho E., Ferreira Z. \& Ayeleso A. (2014) Potential Role of Sulfur-Containing Antioxidant Systems in Highly Oxidative Environments.Molecules 2014, Vol. 19, Pages 19376-19389 19 , 19376-19389.

Nikiforova V., Freitag J., Kempa S., Adamik M., Hesse H. \& Hoefgen R. (2003) Transcriptome analysis of sulfur depletion in Arabidopsis thaliana: Interlacing of biosynthetic pathways provides response specificity. Plant Journal 33 , 633-650.

Nishizawa A., Yabuta Y. \& Shigeoka S. (2008) Galactinol and Raffinose Constitute a Novel Function to Protect Plants from Oxidative Damage. Plant Physiology 147 , 1251-1263.

Niu Y., Wu G.-Z., Ye R., Lin W.-H., Shi Q.-M., Xue L.-J., ... Xue H.-W. (2009) Global Analysis of Gene Expression Profiles in Brassica napus Developing Seeds Reveals a Conserved Lipid Metabolism Regulation with Arabidopsis thaliana. Molecular Plant 2, 1107-1122.

Ohama N., Sato H., Shinozaki K., Yamaguchi-Shinozaki K., Lesk C., al. et, .. a al. et (2016) Transcriptional Regulatory Network of Plant Heat Stress Response. Trends in Plant Science 0 , 84-87.

Pan X., Welti R. \& Wang X. (2010) Quantitative analysis of major plant hormones in crude plant extracts by high-performance liquid chromatography-mass spectrometry. Nature Protocols 5 , 986-992.

Pekrun C., Lutman P.J.W. \& Baeumer K. (1997) Germination behaviour of dormant oilseed rape seeds in relation to temperature. Weed Research 37, 419-431.

Poisson E., Trouverie J., Brunel-Muguet S., Akmouche Y., Pontet C., Pinochet X. \& Avice J.C. (2019) Seed yield components and seed quality of oilseed rape are impacted by sulfur fertilization and its interactions with nitrogen fertilization. Frontiers in Plant Science 10 .

Prerostova S., Dobrev P.I., Kramna B., Gaudinova A., Knirsch V., Spichal L., Zatloukal M., Vankova R. (2020) Heat Acclimation and Inhibition of Cytokinin Degradation Positively Affect Heat Stress Tolerance of Arabidopsis. Frontiers in Plant Science 11, 1-14.

Ruuska S.A., Girke T., Benning C. \& Ohlrogge J.B. (2002) Contrapuntal Networks of Gene Expression during Arabidopsis Seed Filling. The Plant Cell 14, 1191-1206.

Sage T.L., Bagha S., Lundsgaard-Nielsen V., Branch H.A., Sultmanis S. \& Sage R.F. (2015) The effect of high temperature stress on male and female reproduction in plants. Field Crops Research 182, 30-42.

Schulte L.R., Ballard T., Samarakoon T., Yao L., Vadlani P., Staggenborg S. \& Rezac M. (2013) Increased growing temperature reduces content of polyunsaturated fatty acids in four oilseed crops. Industrial Crops and Products 51, 212-219.

Serrano N., Ling Y., Bahieldin A. \& Mahfouz M.M. (2019) Thermopriming reprograms metabolic homeostasis to confer heat tolerance.Scientific Reports $\mathbf{9}, 1-14$.

Sharma M. \& Laxmi A. (2016) Jasmonates: Emerging Players in Controlling Temperature Stress Tolerance. Frontiers in Plant Science6, 1129.

Shu K., Liu X., Xie Q. \& He Z. (2016) Two Faces of One Seed: Hormonal Regulation of Dormancy and Germination. Molecular Plant9, 34-45. 
Soares C., Carvalho M.E.A., Azevedo R.A. \& Fidalgo F. (2019) Plants facing oxidative challenges - A little help from the antioxidant networks. Environmental and Experimental Botany 161 , 4-25.

Soengas P., Rodriguez V.M., Velasco P. \& Cartea M.E. (2018) Effect of Temperature Stress on Antioxidant Defenses in Brassica oleracea.ACS Omega 3 , 5237-5243.

Szydłowska-Czerniak A., Amarowicz R. \& Szłyk E. (2010) Antioxidant capacity of rapeseed meal and rapeseed oils enriched with meal extract.European Journal of Lipid Science and Technology 112, 750-760.

Toh S., Kamiya Y., Kawakami N., Nambara E., McCourt P. \& Tsuchiya Y. (2012) Thermoinhibition uncovers a role for strigolactones in arabidopsis seed germination. Plant and Cell Physiology53 , 107-117.

Trnka M., Rötter R.P., Ruiz-Ramos M., Kersebaum K.C., Olesen J.E., Žalud Z. \& Semenov M.A. (2014) Adverse weather conditions for European wheat production will become more frequent with climate change. Nature Climate Change 4, 637-643.

Tuan P.A., Yamasaki Y., Kanno Y., Seo M. \& Ayele B.T. (2019) Transcriptomics of cytokinin and auxin metabolism and signaling genes during seed maturation in dormant and non-dormant wheat genotypes.Scientific Reports $\mathbf{9}, 1-7$.

Wahid A., Gelani S., Ashraf M. \& Foolad M.R. (2007) Heat tolerance in plants: An overview. Environmental and Experimental Botany61, 199-223.

Wang X., Cai J., Liu F., Dai T., Cao W., Wollenweber B. \& Jiang D. (2014) Multiple heat priming enhances thermo-tolerance to a later high temperature stress via improving subcellular antioxidant activities in wheat seedlings. Plant Physiology and Biochemistry 74, 185-192.

Wang X. \& Liiang D. (2017) Priming: A promising strategy for crop production in response to future climate. Journal of Integrative Agriculture 16 , 2709-2716.

Wang X., Xin C., Cai J., Zhou Q., Dai T., Cao W. \& Jiang D. (2016) Heat Priming Induces Transgenerational Tolerance to High Temperature Stress in Wheat. Frontiers in plant science $\mathbf{7}, 501$.

Xia X.J., Zhou Y.H., Shi K., Zhou J., Foyer C.H. \& Yu J.Q. (2015) Interplay between reactive oxygen species and hormones in the control of plant development and stress tolerance. Journal of Experimental Botany 66 , 2839-2856.

Xie Z., Zhang Z.-L., Hanzlik S., Cook E. \& Shen Q.J. (2007) Salicylic acid inhibits gibberellin-induced alpha-amylase expression and seed germination via a pathway involving an abscisic-acid-inducible WRKY gene. Plant Molecular Biology 64, 293-303.

Young L.W., Wilen R.W. \& Bonham-Smith P.C. (2004) High temperature stress of Brassica napus during flowering reduces micro- and megagametophyte fertility, induces fruit abortion, and disrupts seed production. Journal of Experimental Botany 55, 485-495.

Tables

Table 1: Yield and yield components distinguishing the two pools of pods (i.e. $\operatorname{pods}_{\mathrm{L}<5 \mathrm{~cm}} \operatorname{pods}_{\mathrm{L}[?] 5 \mathrm{~cm}}$ at the beginning of the T-modality application) for the two $\mathrm{S}$ conditions (HS and LS) under the T-modalities. For a given $\mathrm{S}$ condition, letters indicate the ranking among T-modalities (including T-control) (Tukey multiple comparisons test). For a given T-modality, symbols in the HS column indicate significant differences between HS and LS conditions (T-test). F-values and levels of significance are given for $\mathrm{S}, \mathrm{T}$ and $\mathrm{T} \times \mathrm{S}$ effects. Levels of significance: ns non-significant. $p<0.05^{*}, p<0.01^{* *}, p<0.001^{* * *}$.

\begin{tabular}{lllllllll}
\hline S condition & HS & HS & HS & HS & HS & LS & LS & LS \\
T-modality & Mod 1 & Mod 2 & Mod 3 & Mod 4 & Control & Mod 1 & Mod 2 & Mod 3 \\
Total Seed Yield (g) & 7.52 b ns & 8.82 ab ns & 9.61 a ns & 9.55 a ns & 9.92 a ns & 8.78 a & 8.71 a & 8.95 a \\
Total Seed Number & 2519 a ns & 2672 a ns & 2882 a ns & 2802 a ns & 2774 a ns & 2474 a & 2457 a & 2565 a
\end{tabular}




\begin{tabular}{|c|c|c|c|c|c|c|c|c|}
\hline Pods L[?]5cm - Yield (g) & 6.18 a ns & $6.71 \mathrm{a} \mathrm{ns}$ & $6.62 \mathrm{a} \mathrm{ns}$ & $7.21 \mathrm{a} \mathrm{ns}$ & $5.76 \mathrm{a} \mathrm{ns}$ & $6.23 \mathrm{a}$ & $7.06 \mathrm{a}$ & $6.9 \mathrm{a}$ \\
\hline Pods L[?] $5 \mathrm{~cm}$ - Seed Number & 2048 a ns & 1943 a ns & 1981 a ns & 2093 a ns & 1539 a ns & $1856 \mathrm{a}$ & $1956 \mathrm{a}$ & $1896 \mathrm{a}$ \\
\hline Pods L[?] $5 \mathrm{~cm}$ - TSW (g) & $3.07 \mathrm{a} \mathrm{ns}$ & $3.47 \mathrm{a} \mathrm{ns}$ & $3.39 \mathrm{a} \mathrm{ns}$ & $3.47 \mathrm{a}^{*}$ & $3.73 \mathrm{a} n s$ & $3.26 \mathrm{a}$ & $3.63 \mathrm{a}$ & $3.66 \mathrm{a}$ \\
\hline Pods L $<5 \mathrm{~cm}-$ TSW (g) & $2.63 \mathrm{a} \mathrm{ns}$ & $2.95 \mathrm{a} \mathrm{ns}$ & $3.31 \mathrm{a} \mathrm{ns}$ & $3.36 \mathrm{a} \mathrm{ns}$ & $3.33 \mathrm{a} \mathrm{ns}$ & $3.83 \mathrm{a}$ & $3.16 \mathrm{a}$ & $2.97 \mathrm{a}$ \\
\hline
\end{tabular}

Table 2 : Nutritional seed quality criteria measured in seeds from pods $\mathrm{L}_{\mathrm{L}[?]} 5 \mathrm{~cm}$ for the two $\mathrm{S}$ conditions (HS and LS) under the T-modalities. For a given $\mathrm{S}$ condition, letters indicate the ranking among T-modalities (including T-control) (Tukey multiple comparisons test). For a given T-modality, symbols in the HS column indicate significant differences between HS and LS conditions (T-test). F-values and levels of significance are given for $\mathrm{S} . \mathrm{T}$ and $\mathrm{T} \times \mathrm{S}$ effects. Levels of significance: ns non-significant. $p<0.05^{*}, p<0.01^{* *}, p<0.001^{* * *}$

\begin{tabular}{|c|c|c|}
\hline S condition & HS & HS \\
\hline T-modality & Mod 1 & Mod 2 \\
\hline Seed C. $\mathrm{N}$ and $\mathrm{S}$ concentrations $(\% \mathrm{DW})$ & Seed C. $\mathbf{N}$ and $\mathrm{S}$ concentrations (\%DW) & Seed C. $N$ and $S$ conc \\
\hline Carbon $(\% \mathrm{C})$ & $55.38 \mathrm{~b}$ ns & $58.12 \mathrm{ab} \mathrm{ns}$ \\
\hline Nitrogen $(\% \mathrm{~N})$ & $3.97 \mathrm{a} \mathrm{ns}$ & $3.44 \mathrm{ab} \mathrm{ns}$ \\
\hline Sulfur $(\% \mathrm{~S})$ & $0.42 \mathrm{a}^{* *}$ & $0.38 \mathrm{a}^{* *}$ \\
\hline Oil contents and fatty acids (\%DW) & Oil contents and fatty acids (\%DW) & Oil contents and fatty \\
\hline Total Fatty Acids & $30.10 \mathrm{~b} *$ & $36.43 \mathrm{ab}^{* *}$ \\
\hline Total Saturated FAs (SFAs) & $2.91 \mathrm{a} \mathrm{ns}$ & $3.07 \mathrm{a}^{*}$ \\
\hline Total Unsaturated FAs (UFAs) & $27.19 \mathrm{~b} *$ & $33.37 \mathrm{ab} * *$ \\
\hline $\mathrm{C} 18: 2 / \mathrm{C} 18: 3(\omega 6 / \omega 3)$ ratio & $2.29 \mathrm{a} n \mathrm{~s}$ & $1.83 \mathrm{~b} \mathrm{~ns}$ \\
\hline Seed Storage Protein concentrations & Seed Storage Protein concentrations & Seed Storage Protein \\
\hline Total content (mg/g MS) & $118.26 \mathrm{a}^{*}$ & 149.97 a ns \\
\hline
\end{tabular}

Table 3: Seed physiological quality criteria measured in seeds from $\operatorname{pods}_{\mathrm{L}[?]} 5 \mathrm{~cm}$ for the two $\mathrm{S}$ conditions (HS and LS) under the T-modalities. For a given $\mathrm{S}$ condition, letters indicate the ranking among T-modalities (including T-control) (Tukey multiple comparisons test). For a given T-modality, symbols in the HS column indicate significant differences between HS and LS conditions (T-test). F-values and levels of significance are given for $\mathrm{S} . \mathrm{T}$ and $\mathrm{T} \times \mathrm{S}$ effects. Levels of significance: ns non-significant. $p<0.05^{*}, p<0.01^{* *}, p<0.001^{* * *}$

\begin{tabular}{llc}
\hline S condition & HS & HS \\
T-modality & Mod 1 & Mod 2 \\
Soluble sugar concentrations (\%DW) & Soluble sugar concentrations (\%DW) & $2.95 \mathrm{~b}$ \\
Sucrose & $3.69 \mathrm{ab} \mathrm{ns}$ & $0.21 \mathrm{~b}$ \\
Raffinose & $0.25 \mathrm{ab} \mathrm{ns}$ & $1.15 \mathrm{~b}$ \\
Stachyose & $1.40 \mathrm{~b} \mathrm{~ns}$ & $0.46 \mathrm{a}$ \\
[raffinose+stachyose]:sucrose & $0.44 \mathrm{a} \mathrm{ns}$ & Horm \\
Hormone concentrations (ng/g DW) & Hormone concentrations (ng/g DW) & $55.59 \mathrm{~b}$ \\
Abscisic Acid (ABA) & $70.06 \mathrm{a} * * *$ & 134.98 \\
Gibberellic Acid (GA3) & $94.67 \mathrm{~d} * * *$ & 121.74 \\
Indole-3-Acetic Acid (IAA) & $268.92 \mathrm{~b} * * *$ & $1.23 \mathrm{c}$ \\
Jasmonic Acid (JA) & $2.32 \mathrm{a} * * *$ & $42.63 \mathrm{~d}$ \\
Salicylic Acid (SA) & $103.07 \mathrm{~b} *$ & $0.41 \mathrm{c}$ \\
ABA:GA3 ratio & $0.74 \mathrm{a} \mathrm{***}$ & Seed c \\
Seed conductivity & Seed conductivity & $1.28 \mathrm{ab}$ \\
Conductivity ( $\mu$ S/mg) & $2.86 \mathrm{a} \mathrm{ns}$ & Pheno \\
Phenolic concentration and antioxidant capacity & Phenolic concentration and antioxidant capacity
\end{tabular}


Table 4 : Illustration of the additive and non-additive effects observed in yield and the main seed quality criteria among the T-modality events under HS and LS. For a given quality criterion, results display (i) the value of the criteria from Tables 1. 2 and 3; (ii) the observed relative difference between the modality and the control $(\Delta \%)$. The SEScml effects (i.e. Mod2+Mod3 effects) were calculated by multiplying both individual effects to take into account the sequential effect (see Materials and Methods). Bold values are used to identify the mismatches between $\Delta(\%)$ in the CES $(\bmod 1)$ and $\Delta(\%)$ in SEScml $(\bmod 2+\bmod 3)$.

\begin{tabular}{lllllllll}
\hline HS condition & TSY & TSY & $\mathbf{\% N}$ & $\mathbf{\% N}$ & Total FAs & Total FAs & RFOs ratio & RFOs ratio \\
\hline T-modality & Value & $\boldsymbol{\Delta}(\boldsymbol{\%})$ & Value & $\boldsymbol{\Delta}(\boldsymbol{\%})$ & Value & $\boldsymbol{\Delta}(\boldsymbol{\%})$ & Value & $\boldsymbol{\Delta}(\boldsymbol{\%})$ \\
T-control & 9.92 & - & 3.36 & - & 39.35 & - & 0.43 & - \\
Mod1 & 7.52 & $\mathbf{- 2 4 . 2}$ & 3.97 & $\mathbf{+ 1 8 . 2}$ & 30.10 & $\mathbf{- 2 3 . 5}$ & 0.44 & $\mathbf{+ 2 . 3}$ \\
Mod2 & 8.82 & -11.1 & 3.44 & +2.4 & 36.43 & -7.4 & 0.46 & +6.9 \\
Mod3 & 9.61 & -3.1 & 3.32 & -1.2 & 31.16 & -20.8 & 0.35 & -18.6 \\
Mod2+Mod3 effect & & $\mathbf{- 1 4 \%}$ & & $\mathbf{+ 1 \%}$ & & $\mathbf{- 2 3 \%}$ & & $\mathbf{- 1 3 \%}$ \\
\hline
\end{tabular}

\begin{tabular}{lllllllll}
\hline LS condition & TSY & TSY & $\mathbf{\% N}$ & $\mathbf{\% N}$ & Total FAs & Total FAs & RFOs ratio & RFOs ratio \\
\hline T-modality & Value & $\boldsymbol{\Delta}(\boldsymbol{\%})$ & Value & $\boldsymbol{\Delta}(\boldsymbol{\%})$ & Value & $\boldsymbol{\Delta}(\boldsymbol{\%})$ & Value & $\boldsymbol{\Delta}(\boldsymbol{\%})$ \\
T-control & 9.70 & - & 3.11 & - & 39.20 & - & 0.39 & - \\
Mod1 & 8.78 & $\mathbf{- 9 . 5}$ & 3.79 & $\mathbf{+ 2 1 . 9}$ & 35.03 & $\mathbf{- 1 0 . 6}$ & 0.39 & $\mathbf{0 \%}$ \\
Mod2 & 8.71 & -10.2 & 3.51 & +12.9 & 44.48 & +13.5 & 0.45 & +15.4 \\
Mod3 & 8.95 & -7.7 & 3.46 & +11.3 & 42.58 & +8.6 & 0.34 & -12.8 \\
Mod2+Mod3 effect & & $\mathbf{- 1 7 \%}$ & & $\mathbf{+ 2 6 \%}$ & & $\mathbf{+ 2 3 \%}$ & & $\mathbf{+ 1 \%}$ \\
\hline
\end{tabular}

Figure Legends

Figure 1: (a) Schematic of the experimental design for assessing different temperature modalities (Tmodalities) on seed yield and seed quality and (b) recordings of hourly temperatures during the temperature modality application in both heated and control greenhouse units.

The four T-modalities and the control condition (T-control) were applied under HS and LS conditions (10 treatments in total). SES: Single-Event Sequence; CES: Combined-Event Sequence.

Figure 2: Summary of the effects of the 3 temperature sequences (SESs and CES) according to S supply on yield components. Nutritional and physiological quality criteria in seeds from pods $\mathrm{s}_{\mathrm{L} \text { ? }] 5 \mathrm{~cm}}$ at the beginning of stress exposure. The effects are given in reference to the ANOVAs in Tables 1, 2 and 3. The trends (increase or decrease relative to the control) are illustrated with the symbols (+) and (-). Symbol size indicates the effect intensity. The S condition in which the effect is observed is specified in red for HS and green for LS. The T-modality in which the $\mathrm{S}$ restriction effect is observed is specified in bold black.

FAs: Fatty Acids; SFAs: saturated FAs; UFAs: unsaturated FAs; SSP: Seed Storage Proteins; Raff: raffinose; Stach: stachyose; Suc: sucrose. 
Figure 1

(a)

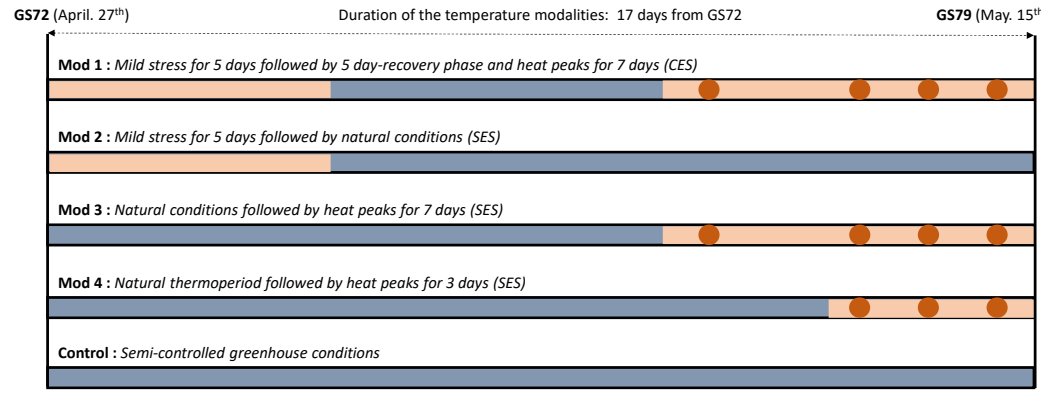

$\square^{\text {Natural conditions }} \quad \square^{\text {Mild stress }}$ Heat Peaks

Figure 2

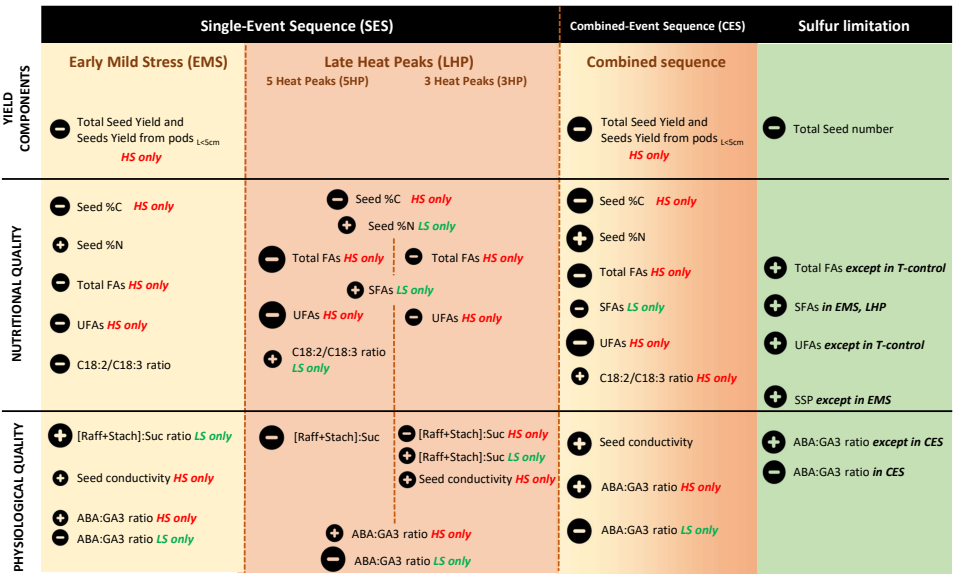

